\title{
Cannabinoid type I receptor antagonists (rimonabant) for smoking cessation (Review)
}

\author{
Cahill K, Ussher M
}

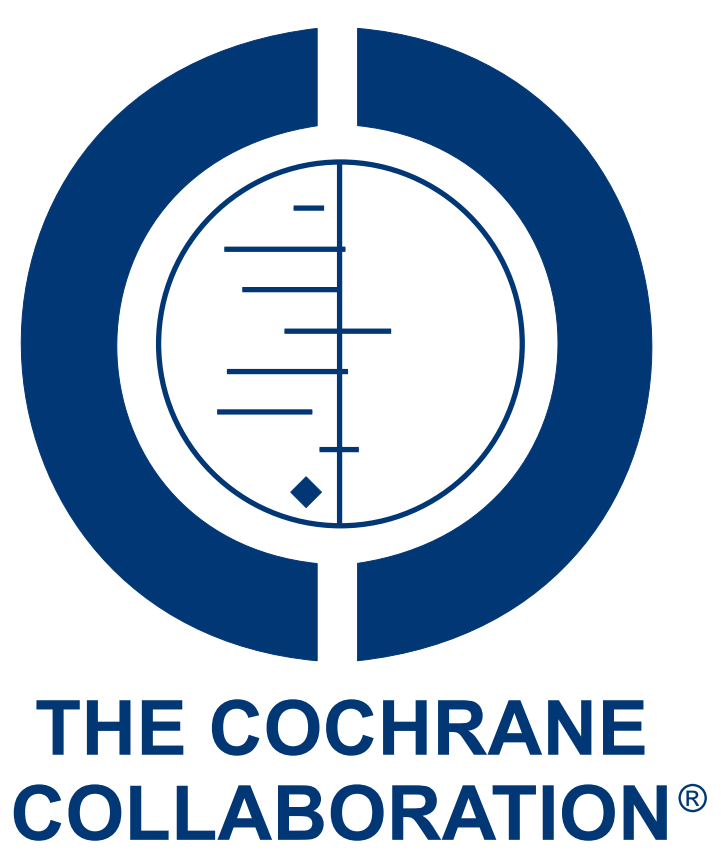

This is a reprint of a Cochrane review, prepared and maintained by The Cochrane Collaboration and published in The Cochrane Library 2007, Issue 3

http://www.thecochranelibrary.com

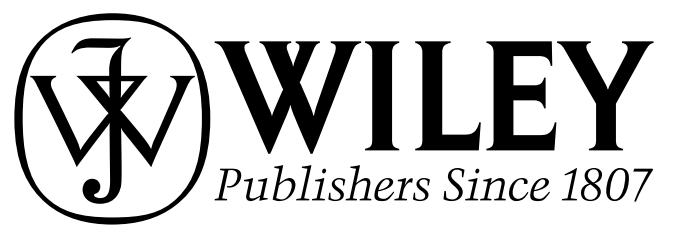

Cannabinoid type I receptor antagonists (rimonabant) for smoking cessation (Review)

Copyright ( 2007 The Cochrane Collaboration. Published by John Wiley \& Sons, Ltd 


\section{TABLE OF CONTENTS}

ABSTRACT . . . . . . . . . . . . . . . . . . . . . . . . . . . . . . . . . . . . . . 1

PLAIN LANGUAGE SUMMARY . . . . . . . . . . . . . . . . . . . . . . . . . . . . . . . . . . . . . . .

BACKGROUND . . . . . . . . . . . . . . . . . . . . . . . . . . . . . . . . . . . . . 2

OBJECTIVES . . . . . . . . . . . . . . . . . . . . . . . . . . . . . . . . . . . . . . . . . . . . . . .

CRITERIA FOR CONSIDERING STUDIES FOR THIS REVIEW . . . . . . . . . . . . . . . . . . . . . . . . . $\quad$. 3

SEARCH METHODS FOR IDENTIFICATION OF STUDIES . . . . . . . . . . . . . . . . . . . . . . . . . . . . . 4

METHODS OF THE REVIEW . . . . . . . . . . . . . . . . . . . . . . . . . . . . . . . . 4

DESCRIPTION OF STUDIES . . . . . . . . . . . . . . . . . . . . . . . . . . . . . . . . . . . . . . 5

METHODOLOGICAL QUALITY . . . . . . . . . . . . . . . . . . . . . . . . . . . . . . . 5

RESULTS . . . . . . . . . . . . . . . . . . . . . . . . . . . . . . . . . . . . . . . . 6

DISCUSSION . . . . . . . . . . . . . . . . . . . . . . . . . . . . . . . . . . . . . . .

AUTHORS' CONCLUSIONS . . . . . . . . . . . . . . . . . . . . . . . . . . . . . . . . . . . . . .

NOTES . . . . . . . . . . . . . . . . . . . . . . . . . . . . . . . . . . . . . . 9

POTENTIAL CONFLICT OF INTEREST . . . . . . . . . . . . . . . . . . . . . . . . . . . . . . . . 9

ACKNOWLEDGEMENTS . . . . . . . . . . . . . . . . . . . . . . . . . . . . . . . . . . . . . . . . . 9

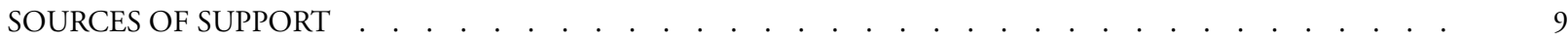

REFERENCES . . . . . . . . . . . . . . . . . . . . . . . . . . . . . . . . . . . . . . . . . . . . . . . . . . . . . 9

TABLES . . . . . . . . . . . . . . . . . . . . . . . . . . . . . . . . . . . . . . . . . .

Characteristics of included studies . . . . . . . . . . . . . . . . . . . . . . . . . . . . . . . .

Characteristics of excluded studies . . . . . . . . . . . . . . . . . . . . . . . . . . . . . . 12

ADDITIONAL TABLES . . . . . . . . . . . . . . . . . . . . . . . . . . . . . . . . . . . . . . . . . . . . .

Table 01 . Glossary of terms . . . . . . . . . . . . . . . . . . . . . . . . . . . . . . . . . . . . . . . .

ANALYSES . . . . . . . . . . . . . . . . . . . . . . . . . . . . . . . . . . . . . . . 14

Comparison 01. Rimonabant $20 \mathrm{mg}$ vs placebo c . . . . . . . . . . . . . . . . . . . . . . . . . . . . . . . $\quad$. 14

Comparison 02. Relapse prevention . . . . . . . . . . . . . . . . . . . . . . . . . . . . . . . . . 15

Comparison 03. Rimonabant $5 \mathrm{mg}$ vs placebo . . . . . . . . . . . . . . . . . . . . . . . . . . . . . . . . . . 15

Comparison 04. Rimonabant $20 \mathrm{mg}$ vs rimonabant $5 \mathrm{mg}$. . . . . . . . . . . . . . . . . . . . . . . . . . . . 15

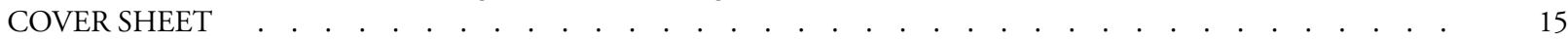

GRAPHS AND OTHER TABLES . . . . . . . . . . . . . . . . . . . . . . . . . . . . . . . . . . . . . . . . . . $\quad . \quad 16$

Analysis 01.01. Comparison 01 Rimonabant 20mg vs placebo, Outcome 01 Prolonged abstinence at wk $50 \quad$. $\quad . \quad$. $\quad 16$

Analysis 01.02. Comparison 01 Rimonabant 20mg vs placebo, Outcome 02 Continuous 4-wk abstinence at EOT (wks 17 7-10)

Analysis 02.01. Comparison 02 Relapse prevention, Outcome 01 rimonabant $20 \mathrm{mg}$ vs placebo at 52 weeks $\quad . \quad$. $\quad 17$

Analysis 02.02. Comparison 02 Relapse prevention, Outcome 02 rimonabant $5 \mathrm{mg}$ vs placebo at 52 weeks $\quad . \quad$. $\quad . \quad 18$

Analysis 03.01. Comparison 03 Rimonabant $5 \mathrm{mg}$ vs placebo, Outcome 01 Prolonged abstinence at wk 50 . . . . . 18

Analysis 03.02. Comparison 03 Rimonabant 5mg vs placebo, Outcome 02 Continuous 4-wk abstinence at EOT (wks 7- 19 10)

Analysis 04.01. Comparison 04 Rimonabant 20mg vs rimonabant 5mg, Outcome 01 Prolonged abstinence at wk 50

Analysis 04.02. Comparison 04 Rimonabant 20mg vs rimonabant 5mg, Outcome 02 Continuous 4-wk abstinence at 20

EOT (wks 7-10) 


\title{
Cannabinoid type I receptor antagonists (rimonabant) for smoking cessation (Review)
}

\author{
Cahill K, Ussher M
}

Status: New

This record should be cited as:

Cahill K, Ussher M. Cannabinoid type 1 receptor antagonists (rimonabant) for smoking cessation. Cochrane Database of Systematic Reviews 2007, Issue 3. Art. No.: CD005353. DOI: 10.1002/14651858.CD005353.pub2.

This version first published online: 18 July 2007 in Issue 3, 2007.

Date of most recent substantive amendment: 22 April 2007

\section{A B S T R A C T}

\section{Background}

Rimonabant is a selective type 1 cannabinoid (CB1) receptor antagonist. It may assist with smoking cessation by restoring the balance of the endocannabinoid system, which can be disrupted by prolonged use of nicotine. Rimonabant also seeks to address many smokers' reluctance to persist with a quit attempt because of concerns about weight gain.

\section{Objectives}

- To determine whether selective CB1 receptor antagonists increase the numbers of people stopping smoking

- To assess their effects on weight change in successful quitters and in those who try to quit but fail.

Search strategy

We searched the Cochrane Tobacco Addiction Review Group specialized register for trials, using the terms 'rimonabant' and 'smoking' in the title or abstract, or as keywords. We also searched MEDLINE, EMBASE, CINAHL and PsycINFO, using major MESH terms. We acquired electronic or paper copies of posters of preliminary trial results presented at the American Thoracic Society Meeting in 2005, and at the Society for Research on Nicotine and Tobacco European Meeting 2006. We also attempted to contact the authors of ongoing studies of rimonabant, and Sanofi Aventis (manufacturers of rimonabant).

\section{Selection criteria}

Types of studies

Randomized controlled trials

Types of participants

Adult smokers

Types of interventions

Selective CB1 receptor antagonists, such as rimonabant.

Types of outcome measures

The primary outcome is smoking status at a minimum of six months after the start of treatment. We preferred sustained cessation rates to point prevalence, and biochemically verified cessation to self-reported quitting. We regarded smokers who drop out or are lost to follow up as continuing smokers. We have noted any adverse effects of treatment.

A secondary outcome is weight change associated with the cessation attempt.

Data collection and analysis

Two authors checked the abstracts for relevance, and attempted to acquire full trial reports. One author extracted the data, and a second author checked them.

Cannabinoid type I receptor antagonists (rimonabant) for smoking cessation (Review)

Copyright $\odot 2007$ The Cochrane Collaboration. Published by John Wiley \& Sons, Ltd 


\section{Main results}

We found three trials which met our inclusion criteria, covering 1567 smokers (cessation: STRATUS-EU and STRATUS-US), and 1661 quitters (relapse prevention: STRATUS-WW). At one year, the pooled odds ratio (OR) for quitting with rimonabant 20 mg was 1.61 ( $95 \%$ confidence interval (CI) 1.12 to 2.30). No significant benefit was demonstrated for rimonabant at 5 mg dosage. Adverse events included nausea and upper respiratory tract infections.

In the relapse prevention trial, smokers who had quit on the $20 \mathrm{mg}$ regimen were $1 \frac{1}{2}$ times more likely to remain abstinent on either active regimen than on placebo; the OR for the $20 \mathrm{mg}$ maintenance group was 1.49 (95\% CI 1.09 to 2.04, and for the 5 mg maintenance group 1.51 (95\% CI 1.11 to 2.07). There appeared to be no significant benefit of maintenance treatment for the $5 \mathrm{mg}$ quitters.

Weight gain was reported to be significantly lower among the $20 \mathrm{mg}$ quitters than in the $5 \mathrm{mg}$ or placebo quitters. During treatment, overweight or obese smokers tended to lose weight, while normal weight smokers did not.

\section{Authors' conclusions}

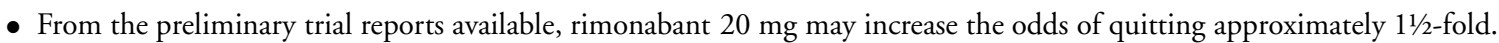

- Adverse events include nausea and upper respiratory tract infections; the risk of serious adverse events is reported to be low.

- The evidence for rimonabant in maintaining abstinence is inconclusive.

- Rimonabant 20 mg may moderate weight gain in the long term.

\section{PLAIN LANGUAGE SUMMARY}

Rimonabant is a selective CB1 receptor antagonist which may help smokers to quit, and may also reduce the amount of weight gained during the quitting process

Long-term use of nicotine can upset the endocannabinoid system in the brain, which controls food intake and energy balance. Rimonabant may help smokers to quit by rebalancing the system, which then reduces nicotine and food cravings. We searched our own specialised register of controlled trials. We also contacted Sanofi-Aventis, the manufacturers of rimonabant, and researchers who presented early findings at conferences. We found two randomized controlled trials (RCTs) of rimonabant for smoking cessation, covering 1567 smokers, and one RCT of rimonabant for relapse prevention covering 1661 quitters. Although full trial reports are not yet published, our own analyses show that rimonabant at the $20 \mathrm{mg}$ dose increased by $1 \frac{1}{2} 2$-fold the odds of not smoking at one year, compared with placebo. Rimonabant $5 \mathrm{mg}$ did no better than placebo at any time point. In the relapse prevention trial, smokers who quit successfully on rimonabant $20 \mathrm{mg}$ were $1 \frac{1 / 2}{2}$ times more likely to remain abstinent on active treatment $(5 \mathrm{mg}$ or $20 \mathrm{mg})$ than on placebo. For those who quit successfully on $5 \mathrm{mg}$, neither active nor placebo treatment appeared to benefit them in avoiding relapse. This inconsistent picture makes it difficult to find a clear benefit for rimonabant in preventing relapse. Although the evidence on weight change is sparse in these trials, weight gain was reported to be significantly lower among the $20 \mathrm{mg}$ quitters than in the $5 \mathrm{mg}$ or placebo quitters. During treatment, overweight or obese smokers tended to lose weight on $20 \mathrm{mg}$, while normal weight smokers did not. Main side effects were nausea and upper respiratory tract infections, and serious harms were reported to be low.

\section{B A C K G R O U N D}

About $70 \%$ of smokers want to quit, with the majority citing concerns about their health as a primary reason for giving up smoking (ONS 2002). There is widespread concern among smokers, however, about the risks of gaining weight after quitting. In the USA it is estimated that $75 \%$ of smokers gain weight when they stop smoking (USPHS 1990), with the majority of the weight gain in the first year of smoking abstinence (O'Hara 1998). Men who sustain abstinence have been shown to gain an average of 4.9 kilograms in the first year of abstinence, and women 5.2 kilograms, with further gains of 2.7 kilograms and 3.5 kilograms respectively across the following four years of abstinence (O'Hara 1998). Other evidence suggests that in the longer term ex-smokers' weight may return to the comparable weight of someone who has never smoked (Mizoue 1998). While some studies have suggested that nicotine replacement therapy or bupropion may moderate post-cessation weight gain (Filozof 2004), no pharmacotherapies are yet available that target both smoking cessation and weight control simultaneously.

The central cannabinoid (CB1) receptors have recently been implicated in brain reward function, and are thought to have a role in controlling food consumption and in dependence and habituation. Excessive eating and fat accumulation are associated with over-activation of the endocannabinoid system, which is involved in the regulation of food intake and energy expenditure. Repeated nicotine use may also overstimulate the endocannabinoid system. 
It is thought that rimonabant may work by selectively blocking the $\mathrm{CB} 1$ receptors,thereby restoring the balance and inhibiting nicotine and food cravings.

Rimonabant (SR 141716; trade name Acomplia) is the first selective cannabinoid type 1 receptor antagonist to have been produced and clinically tested. It was developed initially as a possible treatment for obesity, but it has also been proposed as an aid to smoking cessation and may have the potential to protect successful quitters from significant post-cessation weight gain (ACC 2004; Sanofi-Synth 2004). The development and testing of rimonabant is of particular interest to clinicians, as it may offer an effective and simultaneous treatment for the two major cardiac risk factors of obesity and smoking. Moreover, smoking cessation is itself associated with weight gain. Rimonabant therefore also seeks to address many smokers' reluctance to persist with a quit attempt because of concerns over weight gain (Pomerleau 2000). The beneficial effects of rimonabant on weight loss have been demonstrated in a recent Cochrane review (Curioni 2006).

Rimonabant $20 \mathrm{mg}$ dose has been licensed for use for weight control in the European Union since June 2006, but has not been licensed as a smoking cessation aid. It has not yet been approved by the FDA for sale in the USA. The Summary of Product Characteristics (Acomplia SPC 2006) advises against its use by those with severe hepatic or renal impairment, severe psychiatric illness or lactose intolerance, and advises caution in its use by the elderly, by patients with epilepsy or by those on antidepressant treatment. It is also contra-indicated during pregnancy or while breast-feeding.

Phase III trials have been conducted to test the use of rimonabant for long-term smoking cessation with the avoidance of significant weight gain. The STRATUS program (STudies with Rimonabant And Tobacco USe), has produced conference reports of two cessation trials (STRATUS-EU 2006 and STRATUS-US 2006), and has reported intermediate outcomes for a two-year relapse prevention trial (STRATUS-WW 2005).

\section{O B J E C T IVES}

1. To determine whether selective CB1 receptor antagonists increase the numbers of people stopping smoking.

2. To assess their effects on weight change in successful quitters and in those who try to quit but fail.

\section{CRITERIA FOR CONSIDERING STUDIES FOR THIS REVIEW}

\section{Types of studies}

Randomized controlled trials

\section{Types of participants}

Adult smokers

\section{Types of intervention}

Selective CB1 receptor antagonists, such as rimonabant, and any other drugs of this class as they reach Phase II or Phase III trial stage. The drugs may be used alone or in combination with behavioural therapies or other pharmacotherapies.

\section{Types of outcome measures}

The primary outcome is smoking status at a minimum of six months after the start of treatment. Trials with shorter follow up have not been included in the meta-analysis. We have used sustained cessation rates in preference to point prevalence; sustained cessation refers either to complete abstinence (continuous) or to prolonged abstinence (complete abstinence following a postquit two-week period of grace in which minor relapse may occur) (Hughes 2003). We prefer biochemically verified cessation to selfreported quitting. The strictest definition of smoking cessation reported was used in the meta-analysis. Types of abstinence (continuous, prolonged, point prevalence) and levels of verification (biochemical, self-report) have been considered as potential moderators of outcome. We regard smokers who drop out or are lost to follow up as continuing smokers. We have noted any adverse effects of treatment.

A secondary outcome is change in weight associated with the cessation attempt. We have assessed change in baseline weight at longest follow up (currently one year), and at the end of pharmacotherapy. We have considered weight change in the subgroup of successful quitters, in all those who were randomized, in the subgroup of those who have failed to quit, according to weight classification at baseline, and in the total sample, testing the sensitivity of the results to different ways of handling missing data.

The possible findings include:

(i) Selective CB1 receptor antagonists may increase smoking abstinence rates relative to a control or non-intervention group, and there may be a significantly larger average weight gain in the intervention than in the control group. Interpretation: The weight gain in the intervention group would most probably be due to the higher number of quitters in this group and there would be no evidence to suggest that the intervention has reduced weight gain.

(ii) Selective CB1 receptor antagonists may increase quit rates relative to a control or non-intervention group, but without a significant difference in average weight gain between the groups. Interpretation: This result would be difficult to interpret. It is possible that the intervention may have counteracted some of the anticipated weight gain among the quitters. However, it is also possible that there was a similar weight gain in quitters and continuing smokers independently of the effects of the intervention.

(iii) Selective CB1 receptor antagonists may increase quit rates relative to a control or non-intervention group, and there may 
be a significantly smaller average weight gain in the intervention group than in the control group. Interpretation: This would be good evidence to suggest that the intervention has reduced weight gain.

(iv) There may be no difference in quit rates between the selective CB1 receptor antagonists group and the control group, but a significantly smaller average weight gain in the intervention group than in the control group. Interpretation: This would be evidence for selective CB1 receptor antagonists counteracting weight gain.

Since selective CB1 receptor antagonists may have beneficial effects on other risk factors for the development of cardiovascular disease (Cleland 2004) these outcomes have also been considered.

\section{SEARCH METHODSFOR IDENTIFICATION OF STUDIES}

See: Cochrane Tobacco Addiction Group methods used in reviews.

We searched the Cochrane Tobacco Addiction Review Group specialized register for trials, using the terms 'rimonabant' and 'smoking' in the title or abstract, or as keywords. This register has been developed from electronic searching of MEDLINE, EMBASE, Science Citation Index and PsycINFO, together with handsearching of specialist journals, conference proceedings and reference lists of previous trials and overviews. We have also searched MEDLINE, EMBASE, and PsycINFO, using the major MESH terms (Endocannabinoids-physiology, Receptors,cannabinoid-agonists or Receptors,-cannabinoid-antagonistsand-inhibitors) or equivalent for other databases, combined with $\mathrm{MeSH}$ or free text smoking-related terms (smok* or tobacco or cigar* or nicotine). We have acquired electronic and/or paper copies of posters of preliminary trial results presented at the American Thoracic Society Meeting in 2005, and at the Society for Research on Nicotine and Tobacco European Meeting 2006. We have also attempted to contact the authors of ongoing studies of rimonabant, and Sanofi Aventis (manufacturers of rimonabant).

\section{METHODSOF THE REVIEW}

Two authors checked the abstracts of studies generated by the search strategy for relevance, and attempted to acquire full reports of any trials that might be included in the review, but with only limited success. One author extracted the data, and a second author checked them. Any discrepancies were resolved by mutual consent, or by recourse to the editorial base. We have noted reasons for the non-inclusion of studies.
The following information, where it was available for each trial, is reported in the Table 'Characteristics of Included Studies':

- Country and setting (e.g. primary care, community, hospital outpatient/inpatient).

- Method of selection of participants (e.g. willingness to make a quit attempt).

- Definition of smoker used.

- Method of randomization, and blinding of trialists, participants and assessors.

- Demographic characteristics of participants (e.g. average age, sex, average cigs/day).

- Intervention and control description (provider, length of treatment, number of visits, etc.).

- Outcomes including definition of abstinence used, and biochemical validation of cessation.

- Proportion of participants with follow-up data.

- Any adverse events.

- Secondary outcomes, including weight changes during and after cessation, and other outcomes relevant to cardiovascular risk, including lipid levels.

\section{EVALUATION OF QUALITY}

We evaluated the studies on the basis of the quality of the randomization and allocation concealment procedure used, as described in the Cochrane Handbook. Studies are scored A if a method of randomization and allocation concealment are reported that minimize the chance of selection bias. If insufficient information is available they are scored B, and studies where allocation was not concealed at the point of enrolment are scored C.

We calculated quit rates based on the numbers of patients randomized to an intervention, and excluding any deaths. We have used an intention-to-treat (ITT) analysis, i.e. including all randomized participants in the groups to which they were originally assigned. We have regarded those who drop out or are lost to follow up as continuing smokers. We have noted any deaths and adverse events in the Results section.

\section{WEIGHT CHANGE}

For assessing the impact on weight change we have considered the following outcomes where reported:

- Mean change in weight from baseline (pre-cessation) for confirmed quitters. Since quitting is likely to be associated with weight gain, an examination of the subgroup of successful quitters will provide the most sensitive test of the impact of selective CB1 receptor antagonists on weight gain. 
- Mean weight change from baseline in point prevalence quitters compared with quitters with continuous or prolonged abstinence.

- Mean change in weight from baseline for those failing to quit smoking. This outcome allows an assessment of whether selective CB1 receptor antagonists affect changes in weight among those who relapse or who continue to smoke.

- Mean change in weight from baseline for those completing the study.

- Mean change in weight for those sub-groups who are classed as obese, overweight or normal weight at baseline.

- Mean change in weight from baseline, using an intention-totreat (ITT) analysis, with last weight measure carried forward for study dropouts and losses to follow up. Some of the findings by ITT may be difficult to interpret as quitting is of itself associated with weight gain.

We have considered weight change at the end of pharmacotherapy and at the longest follow up.

Other outcomes relevant to cardiovascular risk, for example lipid levels, have been extracted if reported at long-term follow up.

Where appropriate, we have conducted a meta-analysis of the included studies, using the Mantel-Haenszel odds ratio and a fixedeffect model, provided that there was no significant heterogeneity.

We include in this review the Tobacco Addiction Group glossary of tobacco-specific terms (Table 01).

\section{DESCRIPTIONOFSTUDIES}

We identified three trials which met our inclusion criteria. All were Phase III trials, funded and managed by the makers of rimonabant, Sanofi Aventis. Two trials of identical design (STRATUSEU 2006; STRATUS-US 2006) evaluated rimonabant for smoking cessation, and one trial evaluated rimonabant as an aid to relapse prevention (STRATUS-WW 2005).

The two cessation trials covered 1567 smokers, 1046 of whom were on active treatment ( $20 \mathrm{mg}$ or $5 \mathrm{mg}$ ). The relapse prevention trial began with 5055 smokers, all of whom were on active treatment. During the second phase the 1661 quitters were rerandomized to a maintenence dose of active or placebo treatment for a further 42 weeks. Full details of each trial are given in the Table of Included Studies.

STRATUS-EU 2006 was a multi-centre study, set in seven European countries (Sanofi 2003), while STRATUS-US 2006 was conducted at a clinic in Pennsylvania. The relapse prevention trial (STRATUS-WW 2005) was set in Canada, Australia and the USA.

All three trials tested rimonabant at dosage levels of $5 \mathrm{mg}$ and $20 \mathrm{mg}$, and compared it with a placebo. For the cessation trials, the treatment period was 10 weeks, with a target quit date set for day 15, and follow up for an additional 40 weeks. In the relapse prevention trial (STRATUS-WW 2005) participants who achieved abstinence after 10 weeks of treatment on either a $5 \mathrm{mg}$ or a $20 \mathrm{mg}$ regimen were then re-randomized to either $5 \mathrm{mg}$ or placebo (the $5 \mathrm{mg}$ quitters) or to $5 \mathrm{mg}, 20 \mathrm{mg}$ or placebo (the 20 mg quitters) for a further 42 weeks of relapse prevention treatment. Successful abstainers at one year in this trial were then followed for a further 52 weeks without treatment.

The cessation trials included brief behavioural counselling at weekly visits throughout the treatment phase, covering cessationrelated topics such as craving and relapse prevention, and also diet and exercise but without dietary restrictions. Brief counselling continued at regular clinic visits throughout the follow-up phase. The relapse prevention trial did not report on behavioural support.

The primary outcome for the cessation trials was continuous abstinence through weeks 7 to 10 (end of treatment). Both trials also reported the secondary outcome of continuous abstinence through weeks 2 to 50 , and also 7 -day point prevalence abstinence at weeks 8,10 and 50. Although cessation and/or relapse prevention were the focus of the three trials, all of them also reported weight change as a secondary outcome of interest. The relapse prevention trial also reported on changes in HDL-cholesterol and in triglycerides.

\section{METHODOLOGICAL QUALITY}

None of the trials has yet reported their methods of randomization or allocation concealment, and are therefore rated B (unclear) for their attempts to control selection bias.

In our dependence upon preliminary unpublished reports, we have sometimes found the data to be inconsistent across different sources. The denominators for the STRATUS-EU groups shift between sources and within the same source. We assume that the published reports will present the definitive data.

All three trials defined their abstinence outcome as 'prolonged' i.e. continuous after a post-quit date grace period of two weeks (Hughes 2003), and biochemically verified at each visit by expired carbon monoxide (CO) levels of 10 or fewer parts per million. In the cessation trials, cotinine was also used to verify abstinence at baseline, at weeks 8 and 10, and during the follow-up phase at weeks 14, 32 and 50. The relapse prevention trial used exhaled $\mathrm{CO}$ to verify abstinence during the 10 -week cessation phase, and has not reported its validation procedure for the relapse prevention or the no-treatment phases.

Rates of non-completion of the treatment phase were around $30 \%$ for STRATUS-US 2006, and around 40\% for STRATUS-EU 2006, without significantly different losses between groups. Noncompletion rates for phases 1 and 2 have not been reported for the 
relapse prevention trial, and none of the trials has reported longterm losses to follow up.

\section{RES U L T S}

\section{Cessation}

Both trials (STRATUS-EU 2006; STRATUS-US 2006) detected a benefit of rimonabant $20 \mathrm{mg}$ over placebo for prolonged abstinence at 50 weeks, although the odds ratio (OR) for the STRATUS-EU 2006 trial failed to reach statistical significance (1.31, $95 \%$ confidence interval $[\mathrm{CI}] 0.83$ to 2.09$)$. The pooled OR for the two trials was 1.61 (95\% CI 1.12 to 2.30 ; comparison 01.01). The pooled OR for continuous abstinence at end of treatment (7 to 10 weeks) was similar, at 1.63 (95\% CI 1.21 to 2.19 ; comparison 01.02). No significant benefit of rimonabant $5 \mathrm{mg}$ over placebo was demonstrated at either 50 weeks (OR 1.13, 95\% CI 0.77 to 1.66; comparison 03.01) or at end of treatment (OR 1.15, 95\% CI 0.84 to 1.56 ; comparison 03.02).

We compared the effect of the two doses of rimonabant for prolonged abstinence at 50 weeks and at end of treatment across both trials, and found a modest benefit of the $20 \mathrm{mg}$ regimen over the 5 mg regimen: OR 1.42, 95\% CI 1.00 to 2.02 at 50 weeks (comparison 04.01), and OR 1.42, 95\% CI 1.06 to 1.90 at end of treatment (comparison 04.02).

\section{Relapse prevention}

At the end of the phase 1 10-week treatment regimen in STRATUS-WW 2005, both the $5 \mathrm{mg}$ and the $20 \mathrm{mg}$ groups had similar cessation rates of $31.8 \%$ and $33.6 \%$ respectively. Those $5 \mathrm{mg}$ quitters who were then randomized to the same treatment for phase 2 did not differ significantly from the $5 \mathrm{mg}$ /placebo quitters in relapse rates at 52 weeks. The phase $120 \mathrm{mg}$ quitters who were then randomized to the two active treatment groups in phase 2 maintained significantly higher cessation rates than the placebo group, with an OR for the 20/20 mg group of 1.49 (95\% CI 1.09 to 2.04; comparison 02.01) and an OR for the 20/5 mg group of 1.51 (95\% CI 1.11 to 2.07; comparison 02.02), compared with placebo. Phase 2 participants were scheduled to be followed up for a period of 104 weeks, but at present we have no results beyond the 52-week outcomes described here.

\section{Weight change}

Findings for those maintaining abstinence from smoking:

Among participants maintaining smoking abstinence from 2 to 48 weeks after their quit date, a pooled analysis for STRATUS-EU 2006 and STRATUS-US 2006 shows that those on rimonabant $20 \mathrm{mg}$ gained significantly less weight than those on $5 \mathrm{mg}$ or placebo $(\mathrm{P}<0.05$; STRATUS-EU 2006). There was no significant difference for $5 \mathrm{mg}$ versus placebo. Separate data for the American and European trials were not presented. At the 52-week follow up in STRATUS-WW 2005, among those avoiding relapse to smoking post-cessation weight gain was significantly lower in the rimonabant $20 \mathrm{mg}$ group versus placebo $(\mathrm{P}<0.001)$. Weight gain was similar in the placebo and rimonabant $5 \mathrm{mg}$ groups. The extent of the weight gain in STRATUS-WW 2005 was shown graphically, but not reported as absolute changes in kilos.

In a pooled analysis of STRATUS-US 2006 and STRATUS-EU 2006, among those remaining abstinent from smoking throughout the final four weeks of treatment, those taking rimonabant $20 \mathrm{mg}$ gained significantly less weight than those on placebo $(\mathrm{P}<0.001)$, although it is unclear whether this was measured at ten or at 48 weeks. There were no significant differences when comparing 5 mg rimonabant with placebo. In STRATUS-EU 2006, among non-obese participants, the rimonabant $20 \mathrm{mg}$ users $(\mathrm{N}=54)$ had a mean weight gain of $0.5 \mathrm{~kg}$; for rimonabant $5 \mathrm{mg}$ (users $\mathrm{N}=$ 53) the gain was $1.6 \mathrm{~kg}$; those on placebo $(\mathrm{N}=44)$ gained 2.3 $\mathrm{kg}$. Details of weight changes were not given for STRATUS-US 2006.

\section{Findings using intention-to-treat (ITT) analysis:}

When considering all those smokers who were randomized (ITT analysis), in the STRATUS-US 2006 trial, on average across the 10 -week treatment period, those on rimonabant $20 \mathrm{mg}$ lost 0.3 $\mathrm{kg}$, while those on placebo gained $1.1 \mathrm{~kg}(\mathrm{P}<0.001)$. Participants who were overweight (body mass index [BMI: weight in kg/height in $\mathrm{m} 2]=25$ to 29.9$)$ or obese $(\mathrm{BMI}=30+)$ tended to lose weight using rimonabant $20 \mathrm{mg}$, while normal-weight participants (BMI $=18.5$ to 24.9) did not. Overweight smokers on rimonabant $20 \mathrm{mg}$ lost $0.5 \mathrm{~kg}$ on average, versus a gain of $0.9 \mathrm{~kg}$ for those on placebo. Obese smokers on rimonabant $20 \mathrm{mg}$ lost $0.6 \mathrm{~kg}$ compared with a gain of $1.3 \mathrm{~kg}$ for those on placebo. For those of normal weight there was no weight change when using rimonabant $20 \mathrm{mg}$, but those on placebo gained $1.0 \mathrm{~kg}$. Only the finding for obese smokers reached statistical significance $(\mathrm{P}<0.001)$. Weight change for the rimonabant $5 \mathrm{mg}$ group was not reported.

Again using an ITT analysis, in STRATUS-EU 2006 those on rimonabant $20 \mathrm{mg}(\mathrm{N}=267)$ lost $0.5 \mathrm{~kg}$, while those on placebo $(\mathrm{N}$ $=260)$ and $5 \mathrm{mg}(\mathrm{N}=256)$ gained $1.0 \mathrm{~kg}$ and $0.2 \mathrm{~kg}$ respectively, across the treatment period. In STRATUS-WW 2005, among all re-randomized participants at the 52 week follow-up, those on rimonabant $20 \mathrm{mg}(\mathrm{N}=340), 5 \mathrm{mg}(\mathrm{N}=335)$ and placebo $(\mathrm{N}=342)$ gained an average of $0.6 \mathrm{~kg}, 1.9 \mathrm{~kg}$ and $2.0 \mathrm{~kg}$ respectively. As with STRATUS-US 2006, for STRATUS-EU 2006 and STRATUSWW 2005 the difference in weight gain for $20 \mathrm{mg}$ versus placebo reached statistical significance $(\mathrm{P}=0.001, \mathrm{P}<0.001$ respectively). Where there were missing data, the ITT analysis for STRATUSEU 2006 and STRATUS-WW 2005 was based on 'last observation carried forward'. It is not clear whether this approach was also used for the ITT analysis for STRATUS-US 2006.

\section{Adverse events:}

The three trials demonstrated disparate patterns of adverse events. STRATUS-US 2006 reported nausea as the most frequent side effect, occurring in $15.7 \%$ of the $20 \mathrm{mg}$ group compared with $9.2 \%$ in the $5 \mathrm{mg}$ group and $8.8 \%$ in the control group (differences 
not statistically significant). This paralleled the predominance and rates of nausea as the main side effect reported in the RIO trials, which tested rimonabant as a treatment for weight control (Curioni 2006). Nausea was not mentioned as a significant side effect in STRATUS-EU 2006, which listed fatigue, depressed mood, anxiety and nasopharyngitis as the most commonly reported events. Upper respiratory tract infection was the most frequent adverse event for the STRATUS-WW 2005 participants, at around 18\% across all groups, with nasopharyngitis as the next most commonly reported event (mean 10.5\% across all groups). Again, nausea was not mentioned as a significant side effect for any group in this trial. It should be noted, however, that the Summary of Product Characteristics (Acomplia SPC 2006) reports the incidence of nausea and upper respiratory tract infections as 'very common' (i.e. > 10\%) when rimonabant is used for weight control.

Drop-out rates attributable to adverse events were consistently highest in the $20 \mathrm{mg}$ groups and lowest in the control groups, with only STRATUS-EU 2006 reporting a statistically significantly higher drop-out rate in the $20 \mathrm{mg}$ group (14.6\%) compared with the placebo group $\left(6.9 \% ; \mathrm{X}^{2} 8.22, \mathrm{P}=0.004\right)$. STRATUS-EU 2006 reported significantly higher rates of drop-out attributable to adverse events across all groups (placebo $6.9 \%, 5 \mathrm{mg}$ 9.8\%, $20 \mathrm{mg}$ 14.6\%) compared with STRATUS-US 2006 (3.8\%, $5.7 \%, 6.9 \%$ respectively) and with STRATUS-WW 2005 (6.1\%, $6.3 \%, 9.7 \%$ respectively). However, the STRATUS-EU 2006 attributable drop-out rates were similar to those reported in the four RIO trials (Curioni 2006).

Information on serious adverse events (SAEs) is sparse at present. At one year follow up, STRATUS-WW 2005 reports SAE rates of $5 \%, 3.6 \%$ and $5.3 \%$ in placebo, $5 \mathrm{mg}$ and $20 \mathrm{mg}$ groups respectively. The corresponding figures for STRATUS-EU 2006 are $2.7 \%, 0.8 \%$ and $2.2 \%$, i.e. the placebo group reporting the highest rate, but with a statistically non-significant difference. STRATUSUS 2006 has not reported separate group rates, but has confirmed that no cardiovascular safety concerns were raised by their findings. A pooled analysis of STRATUS-EU, STRATUS-META and STRATUS-US reports SAEs running at $2 \%$ in the rimonabant 20 mg group compared with $2.2 \%$ in the placebo group (STRATUS META 2006). This may be compared with SAE rates in the RIO (rimonabant in obesity) trials, which ranged from $4 \%$ to $8 \%$, with a pooled relative risk increase of 1.37 (95\% CI 1.04 to $1.80, \mathrm{P}=$ 0.03 ) in the $20 \mathrm{mg}$ groups compared with placebo groups (Curioni 2006).

\section{I S C USSION}

Our review has suffered from a lack of peer-reviewed and published study reports. Despite our best efforts to obtain information, we have had to rely on conference presentations, press releases and pharmaceutical company reports, and we are aware that the findings of this review are tentative and incomplete. We look forward to the eventual disclosure of methodological details, including randomization and allocation procedures, exclusion criteria, verification methods, and levels of behavioural support. We also await full details of attrition rates, losses to follow up, individual trial results and comprehensive long-term outcome data. Furthermore, all the trials reviewed so far were sponsored by the pharmaceutical company manufacturing rimonabant. Since conflicts of interest could influence the results, their findings should be treated with caution.

\section{Smoking cessation}

The two cessation trials have detected a benefit of rimonabant 20 mg over placebo at longest reported follow up, with a statistically significant pooled OR of 1.6. There was also a modest but significant benefit of the $20 \mathrm{mg}$ dose over the $5 \mathrm{mg}$ dose (pooled OR 1.42). These data are compatible with rimonabant's failure at the $5 \mathrm{mg}$ dose to out-perform placebo treatment in these trials.

The pooled results mask the differential between the findings of the two trials. STRATUS-EU 2006 consistently failed to demonstrate the superiority of rimonabant $20 \mathrm{mg}$ over either placebo or rimonabant $5 \mathrm{mg}$ for prolonged abstinence at either 50 weeks or at end of treatment (7 to 10 weeks). STRATUS-US 2006 found statistically significant benefits for the $20 \mathrm{mg}$ regimen for both comparisons and at both time points. The failure of rimonabant $20 \mathrm{mg}$ to establish a significant benefit in the STRATUS-EU 2006 trial can be largely attributed to an exceptionally high placebo quit rate (19.6\% at end of treatment, $14.6 \%$ at 50 weeks). This sustained discrepancy between the trial findings will need to be explored when more information is made available.

\section{Relapse prevention}

It is worth noting that for the phase 1 (cessation) $20 \mathrm{mg}$ quitters in STRATUS-WW 2005, those randomized to a $5 \mathrm{mg}$ maintenance dose (OR of 1.51 compared with placebo at 52 weeks) did at least as well as those randomized to a $20 \mathrm{mg}$ maintenance dose (OR 1.49). This finding is difficult to interpret; considering only the phase 1 $20 \mathrm{mg}$ quitters, it would suggest that the lower dose of maintenance therapy is as effective as the higher dose, and that both regimens yield better success rates than placebo treatment. However, for the phase $15 \mathrm{mg}$ quitters, randomized to either a further $5 \mathrm{mg}$ or to placebo during the maintenance phase, the active treatment group did no better than the placebo group, suggesting that the presence or absence of treatment made no difference during the maintenance phase. Since the quit rates in both phase 1 groups were similar (31.8\% in the $5 \mathrm{mg}$ group versus $33.6 \%$ in the 20 mg group), we have no consistent evidence from this trial for the relative efficacy of the two doses, either for cessation or for maintenance. We also await information on the phase 3 findings, which will cover a further 52 weeks without treatment.

\section{Weight change}

Among abstinent smokers, we found a statistically significant effect of rimonabant $20 \mathrm{mg}$ on body weight. Compared with placebo, rimonabant $20 \mathrm{mg}$ produced significantly less weight gain at end 
of treatment in two trials. Only one of these trials reported the magnitude of the weight reduction and only for non-obese participants. In this study those on rimonabant gained $1.8 \mathrm{~kg}$ less than those on placebo. At 48-week follow-up a pooled analysis of the two trials showed that there was significantly less weight gain for rimonabant $20 \mathrm{mg}$ versus placebo, among those maintaining abstinence. However, a separate analysis for each trial was not presented. In the trial of relapse prevention, those avoiding relapse up to 52 weeks gained significantly less weight on rimonabant $20 \mathrm{mg}$ versus placebo, but the magnitude of the weight gain was not given. Using an intention to treat (ITT) approach, one trial showed significantly less weight gain for rimonabant $20 \mathrm{mg}$ versus placebo at end of treatment, and another study showed the same benefit at 52 weeks follow-up. However, both these analyses were based on 'last observation carried forward', which makes interpretation difficult (see comments below). In addition, only one of these trials presented the weight changes and in this study those on rimonabant $20 \mathrm{mg}$ gained just $1.4 \mathrm{~kg}$ less than those on placebo at 52 weeks. The third trial reported a significant benefit of rimonabant $20 \mathrm{mg}$, compared with placebo, on weight gain only for obese individuals. Overall, the findings suggest that rimonabant $20 \mathrm{mg}$ may have a modest benefit for moderating weight gain following smoking cessation both in the short-term and the long-term, but the magnitude of this benefit is not clear and methodological limitations make interpretation problematic. Without further data it is not possible to judge the clinical significance of any benefits for rimonabant on weight gain.

In nearly all cases the magnitude of the weight change was not reported or was reported only for a sub-sample, and in no cases were 95\% confidence intervals given. For two trials the key outcome of weight change among confirmed quitters at the final follow up was reported using only a pooled analysis combining data from both studies. None of the studies presented an analysis exclusively for those who relapsed or continued to smoke. Only one report examined weight changes according to whether participants were obese, overweight or of normal weight at baseline. The outcomes for prolonged smoking cessation were based on the recommended two-week grace period (Hughes 2003), whereas weight change was assessed among those who had abstained following a four-week grace period. It is not clear why this unconventional criterion for prolonged abstinence was used for weight change.

For the ITT analysis, where there were missing weight data the last observation was carried forward. This approach makes the unrealistic assumption that weight remains constant since the last measurement. Consequently, the results may have been biased in either direction. For example, if those on placebo dropped out of the study because they were gaining weight, then carrying the last observation forward is likely to underestimate their weight gain. This may then lead to underestimation of the benefit of rimonabant compared with placebo. Conversely, if some of those on rimonabant withdrew because of weight gain, then carrying their last observation forward may underestimate the mean weight gain in this group. The benefit of rimonabant versus placebo would in that case be overestimated. As the attrition rates were not reported it is not possible to estimate the extent of this problem. High attrition rates would compromise the validity of an ITT analysis. The obvious solution would be to measure all participants, even if they did not adhere to the treatment. Another issue related to drop-outs is that it is possible that some individuals did not take rimonabant as prescribed but still managed to stop smoking with little weight gain and attended the follow-up visits. The number of these individuals is not given, and this may distort the results in a way that overestimates the benefit of rimonabant for weight loss.

\section{A U THORS' CONCLUSIONS}

\section{Implications for practice}

- From the limited evidence available so far, rimonabant $20 \mathrm{mg}$

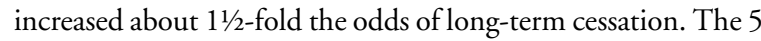
mg dose appeared to confer no significant benefit. However, the trial findings are at present inconsistent and provisional until publication of the full reports.

- Adverse events may be dose-related, and may include upper respiratory tract infection and nausea. The severity and type of adverse event were inconsistent across the three trials included in this review. Rates of serious adverse events were reported to be low.

- Partial study reports, without long-term outcomes at the end of the no-treatment phase, preclude any clear findings on the use of rimonabant for maintenance of abstinence.

- Based on the findings of one study, rimonabant $20 \mathrm{mg}$ may moderate weight gain among those who abstain from smoking for approximately one year. There is insufficient information from the other two trials to substantiate this finding. Implications for future practice will depend upon more detailed published reports on the amount of weight gained and attrition rates.

\section{Implications for research}

- The STRATUS smoking cessation findings will need to be tested through independent population-based trials.

- Rimonabant as an aid to smoking cessation should be directly compared with other pharmacotherapies, such as nicotine replacement therapy, bupropion and varenicline.

- Future research will need to consider the benefits of rimonabant for sub-groups of smokers (e.g. obese versus overweight versus healthy weight). Rimonabant could also be assessed in relation to other cessation interventions that influence weight gain (e.g. nicotine replacement therapy, bupropion, exercise), by direct comparisons and for interactions with those interventions. We await publication of detailed peer-reviewed results of the current 
studies before discussing further implications for future research and practice.

\section{NOTES}

First author (Kate Cahill) published the protocol in 2005 under previous name of Kate Hey.

\section{POTENTIAL CONFLICT OF INTERES T}

None known.

\section{ACKNOWLEDGEMENTS}

We thank David Balfour and Bess Marcus for reading and commenting on the protocol, and David Balfour and John Stapleton for commenting on the full review. We also thank Professor RM Anthenelli for clarifying some data issues on the STRATUS-US trial report from the 2004 ACC Meeting.

\section{SOURCES OF SUPPORT}

\section{External sources of support}

- NHS Research and Development Fund UK

\section{Internal sources of support}

- Department of Primary Health Care, Oxford University UK

- Division of Community Health Sciences, St George's, University of London UK

\section{R E F E R E N C E S}

\section{References to studies included in this review}

STRATUS-EU 2006 \{published and unpublished data\}

* Cinciripini PM, Aubin H-J, Dale LC, Niaura R, Anthenelli RM,

Robinson J. Pooled analysis of three short-term, randomised, doubleblind, placebo-controlled trials with rimonabant $20 \mathrm{mg} / \mathrm{d}$ in smoking cessation [PI-TS-01]. Society for Research on Nicotine and Tobacco 8th European Conference, September 2006, Kusadasi Turkey. 2006.

Sanofi Aventis. Information Meeting. http://en.sanofi-aventis.com/ Images/en_050301_up_2004_Full_Year_Results_Analysts_ Investors_meeting_in_Paris_presentation_tcm24-3612.pdf (accessed 23rd November 2006) 2005.

STRATUS-US 2006 \{published and unpublished data\}

Anthenelli RM, Depres J-P. Effects of rimonabant in the reduction of major cardiovascular risk factors. Results from the STRATUS-US Trial (smoking cessation in smokers motivated to quit) and the RIO-
LIPIDS Trial (weight reducing and metabolic effects in overweight/ obese patients with dyslipidemia. American College of Cardiology Annual Scientific Session. March 2004.

Boyd ST, Fremming BA. Rimonabant - a selective CB1 antagonist. Annals of Pharmacotherapy 2005;39:684-90.

* Cinciripini PM, Aubin H-J, Dale LC, Niaura R, Anthenelli RM, Robinson J. Pooled analysis of three short-term, randomised, doubleblind, placebo-controlled trials with rimonabant $20 \mathrm{mg} / \mathrm{d}$ in smoking cessation [PI-TS-01]. Society for Research on Nicotine and Tobacco 8th European Conference, September 2006, Kusadasi Turkey. 2006.

STRATUS-WW 2005 \{published and unpublished data\}

Niaura R. Long-term maintenance of abstinence from smoking with rimonabant: results from the STRATUS Worldwide trial. 1-year efficacy/safety results. American Thoracic Society Conference 2005. 
Niaura R. Long-term maintenance of abstinence from smoking with rimonabant: reuslts from the STRATUS Worldwide trial. 6-month efficacy/safety results [POS1-054]. American Thoracic Society Conference. 2004.

Sanofi Aventis. Information Meeting. http://en.sanofi-aventis.com/ Images/en_050301_up_2004_Full_Year_Results_Analysts_ Investors_meeting_in_Paris_presentation_tcm24-3612.pdf (accessed 23rd November 2006) 2005.

\section{References to studies excluded from this review}

\section{STRATUS META 2006}

Cinciripini PM, Aubin H-J, Dale LC, Niaura R, Anthenelli RM, Robinson J. Pooled analysis of three short-term, randomised, doubleblind, placebo-controlled trials with rimonabant $20 \mathrm{mg} / \mathrm{d}$ in smoking cessation [PI-TS-01]. Society for Research on Nicotine and Tobacco 8th European Conference, September 2006, Kusadasi Turkey. 2006

\section{Additional references}

\section{ACC 2004}

American College of Cardiology. Data shows new drug, rimonabant, helps smokers quit while limiting post cessation weight gain. www.eurekalert.org/pub_releases/2004-03/k-dsn030904.php (accessed September 15 2004).

\section{Acomplia SPC 2006}

Sanofi-Aventis. Acomplia 20mg Summary of Product Characteristics. http://emc.medicines.org.uk/emc/assets/c/html/displaydoc.asp?documentid=18283 (accessed 18th April 2007) 2006.

\section{Cleland 2004}

Cleland JGF, Ghosh J, Freemantle N, Kaye GC, Nasir M, Clark $\mathrm{AL}$, et al. Clinical trials update and cumulative meta-analyses from the American College of Cardiology: WATCH, SCD-HeFT, DINAMIT, CASINO, INSPIRE, STRATUS-US, RIO-LIPIDS and cardiac resynchronisation therapy in heart failure. European Journal of Heart Failure 2004;6:501-8.

\section{Cochrane Handbook}

Higgins JPT, Green S, editors. Cochrane Handbook for Systematic Reviews of Interventions 4.2.6 [updated September 2006]. http: //www.cochrane.org/resources/handbook/hbook.htm (accessed 18th April 2007) 2006.

\section{Curioni 2006}

Curioni C, Andre C. Rimonabant for overweight or obesity. Cochrane Database of Systematic Reviews 2006, Issue 4. Art. No.: CD006162. DOI:10.1002/14651858.CD006162.pub2.

\section{Filozof 2004}

Filozof C, Pinilla MC, Fernandez-Cruz A. Smoking cessation and weight gain. Obesity Review 2004;5:95-103.

Hughes 2003

Hughes JR, Keely JP, Niaura RS, Ossip-Klein DJ, Richmond RL, Swan GE. Measures of abstinence in clinical trials: issues and recommendations. Nicotine \& Tobacco Research 2003;5(1):13-25.

\section{Mizoue 1998}

Mizoue T, Ueda R, Tokui N, Hino Y, Yoshimura T. Body mass decrease after initial gain following smoking cessation. International Journal of Epidemiology 1998;27:984-8.

\section{O'Hara 1998}

O'Hara P, Connett JE, Lee WW, Nides M, Murray R, Wise R. Early and late weight gain following smoking cessation in the Lung Health Study. American Journal of Epidemiology 1998;148(9):821-30.

\section{ONS 2002}

Office for National Statistics. Smoking-related behaviour and attitudes. http://www.dh.gov.uk/assetRoot/04/06/81/56/04068156. pdf (accessed 11th April 2005).

\section{Pomerleau 2000}

Pomerleau CS, Pomerleau OF, Namenek RJ, Mehringer AM. Shortterm weight gain in abstaining women smokers. Journal of Substance Abuse and Treatment 2000;18(4):339-42.

\section{Sanofi 2003}

Sanofi--Synthelabo. RIO and STRATUSD Clinical Studies Guide. Sanofi-Synthelabo, 2003.

\section{Sanofi-Synth 2004}

Sanofi-Synthelabo. Two pivotal studies indicate ACOMPLIA (rimonabant) offers a novel approach to cardiovascular risk management in overweight/obese people and smokers. http://es.sanofi-synthelabo.com/press/ppc_23804.asp (accessed September 15 2004).

\section{USPHS 1990}

US Public Health Service. The health benefits of smoking cessation: A report of the Surgeon General. DHHS Publication No CDC 908416 1990; Vol. Washington DC.

* Indicates the major publication for the study

T A B LES

\section{Characteristics of included studies}

\begin{tabular}{ll} 
Study & STRATUS-EU 2006 \\
\hline Methods & SMOKING CESSATION \\
& Country: Belgium, Denmark, France, Spain, Sweden, Switzerland, UK \\
& Setting: \\
\hline
\end{tabular}




\section{Characteristics of included studies (Continued)}

Study Design: Double-blind placebo-controlled parallel-assignment RCT.

Analysis: Logistic regression on ITT basis.

Participants

783 adults ( $>=18)$ smoking at least $10 \mathrm{cpd}$. Randomized to rimonabant $5 \mathrm{mg}(\mathrm{N}=256)$, rimonabant $20 \mathrm{mg}$ $(\mathrm{N}=267)$, or placebo $(\mathrm{N}=260)$.

$46 \% \mathrm{M}, 98 \% \mathrm{~W}$, mean age 42.4, av cpd 22.5, mean yrs smoking 24.9, mean quit attempts 2.9, mean FTND score 5.6, 35\% with a FTND score $>7$. Mean BMI 25.0.

Intervention

(i) Rimonabant $5 \mathrm{mg}$ (ii) Rimonabant $20 \mathrm{mg}$ (iii) Placebo tablets

2-wk pre-treatment screening period, then 10 wks treatment, with TQD at day 15.

Behavioural support:

Treatment phase: Participants were seen weekly for $12 \mathrm{wks}(-2$ to $+10 \mathrm{wks})$. Brief behavioural counselling at every visit on tobacco-related topics (e.g. craving, relapse prevention) including diet and exercise, but no dietary restrictions.

Follow-up phase: clinic visits at wks 11, 14, 22, 30, 39, 48.

Outcomes

Primary outcome: Continuous validated abstinence at 7-10 wks. Maximum follow up: 48 wks. Strictest measure of abstinence: Prolonged validated abstinence from tobacco or nicotine products from wk 2 to wk 48.

Validation method: Expired CO $<10 \mathrm{ppm}$ at all visits, + cotinine at baseline, wks 8 and 10, and at wks 14, 32 and 50.

Other outcomes: weight change; adverse events.

\begin{tabular}{ll}
\hline Notes & Identical design to STRATUS-US trial. \\
\hline Allocation concealment & $\mathrm{B}$ - Unclear \\
\hline
\end{tabular}

\begin{tabular}{|c|c|}
\hline Study & STRATUS-US 2006 \\
\hline Methods & $\begin{array}{l}\text { SMOKING CESSATION } \\
\text { Country: USA } \\
\text { Setting: Sanofi Clinic, Pennsylvania } \\
\text { Study Design: Double-blind placebo-controlled parallel-assignment RCT. } \\
\text { Analysis: Logistic regression on ITT basis. }\end{array}$ \\
\hline Participants & $\begin{array}{l}784 \text { adults }(>=18) \text { smoking at least } 10 \mathrm{cpd} \text {. Randomized to rimonabant } 5 \mathrm{mg}(\mathrm{N}=262) \text {, rimonabant } 20 \mathrm{mg} \\
(\mathrm{N}=261) \text {, or placebo }(\mathrm{N}=261) \text {. } \\
51 \% \mathrm{M}, 87 \% \mathrm{~W} \text {, mean age } 42.3 \text {, av cpd } 23.6 \text {, mean yrs smoking } 24.1 \text {, mean quit attempts } 4.1 \text {, mean FTND } \\
\text { score } 5.4,31.7 \% \text { with a FTND score }>7 \text {. Mean BMI } 27.8 \text {. }\end{array}$ \\
\hline Interventions & $\begin{array}{l}\text { (i) Rimonabant } 5 \mathrm{mg} \text { (ii) Rimonabant } 20 \mathrm{mg} \text { (iii) Placebo tablets } \\
\text { 2-wk pre-treatment screening period, then } 10 \text { wks treatment, with TQD at day } 15 . \\
\text { Behavioural support: } \\
\text { Treatment phase: Participants were seen weekly for } 12 \mathrm{wks}(-2 \text { to }+10 \text { wks). Brief behavioural counselling } \\
\text { at every visit on tobacco-related topics (e.g. craving, relapse prevention) including diet and exercise, but no } \\
\text { dietary restrictions. } \\
\text { Follow-up phase: clinic visits at wks } 11,14,22,30,39,48 \text {. }\end{array}$ \\
\hline Outcomes & $\begin{array}{l}\text { Primary outcome: Continuous validated abstinence at } 7-10 \text { wks. Maximum follow up: } 48 \text { wks. Strictest } \\
\text { measure of abstinence: Prolonged validated abstinence from tobacco or nicotine products from wk } 2 \text { to wk } \\
48 \text {. } \\
\text { Validation method: Expired CO <10ppm at all visits, + cotinine at baseline, wks } 8 \text { and } 10 \text {, and at wks } 14 \text {, } \\
32 \text { and } 50 . \\
\text { Other outcomes: weight change; adverse events. }\end{array}$ \\
\hline Notes & Identical design to STRATUS-EU trial. \\
\hline Allocation concealment & B - Unclear \\
\hline
\end{tabular}




\begin{tabular}{|c|c|}
\hline Study & STRATUS-WW 2005 \\
\hline Methods & $\begin{array}{l}\text { RELAPSE PREVENTION TRIAL } \\
\text { Country: Australia, Canada, USA } \\
\text { Study Design: Double-blind placebo-controlled parallel-assignment RCT. } \\
\text { Analysis: Logistic regression on ITT basis. }\end{array}$ \\
\hline Participants & $\begin{array}{l}5055 \text { adult smokers }(>+18) \text { motivated to quit. randomized to rimonabant } 5 \mathrm{mg}(\mathrm{N}=2026) \text { or rimonabant } \\
20 \mathrm{mg}(\mathrm{N}=3029) \text {. } \\
50 \% \mathrm{M}, 88.8 \% \mathrm{~W} \text {, mean age } 44.1 \text {, av cpd } 23.6 \text {, mean yrs smoking } 24.1 \text {, mean quit attempts } 4.1 \text {, mean } \\
\text { FTND score } 5.4,31.7 \% \text { with a FTND score }>7 \text {. Mean BMI } 27.8 \text {. }\end{array}$ \\
\hline Interventions & 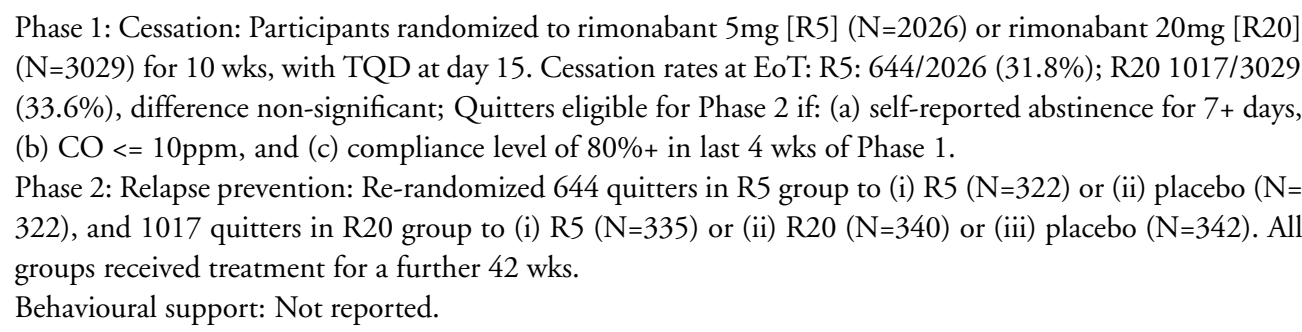 \\
\hline Outcomes & $\begin{array}{l}\text { Primary outcome: Time to relapse for quitters from wks } 10 \text { to } 32 \text {. Relapse defined as }>=7 \text { consecutive days } \\
\text { of smoking (even a puff), or }>=2 \text { consecutive days with }>=5 \text { cigs (even a puff) smoked per day. } \\
\text { Long-term follow up: } 52 \text { wks, } 104 \text { wks. } \\
\text { Secondary outcome: time to relapse for quitters from wks } 10 \text { to } 52 \text {. } \\
\text { Other outcomes: weight change; fasting HDL-cholesterol, triglycerides; safety, adverse events. } \\
\text { Validation: Phase 1: expired CO <10ppm; Phase 2: not reported }\end{array}$ \\
\hline Notes & Two-year follow-up data awaited. \\
\hline Allocation concealment & B - Unclear \\
\hline $\begin{array}{l}\text { BMI: body mass index (me } \\
\text { cpd: cigarettes per day } \\
\text { EoT: end of treatment } \\
\text { FTND: Fagerstrom Test for } \\
\text { ITT: Intention to treat (inc } \\
\text { M: male } \\
\text { TQD: target quit date } \\
\text { W: white }\end{array}$ & $\begin{array}{l}\text { ric measure of weight/height squared) } \\
\text { Nicotine Dependence } \\
\text { udes all randomized in original groups) }\end{array}$ \\
\hline
\end{tabular}

\title{
Characteristics of excluded studies
}

\author{
Study Reason for exclusion
}

STRATUS META 2006 RCT in USA of 530 smokers randomized to rimonabant $20 \mathrm{mg}$ or placebo; cessation reported at 10 wks, EoT, with no long-term follow up.

Cannabinoid type I receptor antagonists (rimonabant) for smoking cessation (Review) 
A D D I T I O N A T A B L ES

Table 01. Glossary of terms

\section{Term}

Abstinence

Biochemical verification

Bupropion

Carbon monoxide (CO)

Cessation

Continuous abstinence

'Cold Turkey'

Craving

Dopamine

Efficacy

Harm reduction

Lapse/slip

nAChR

Nicotine

\section{Definition}

A period of being quit, i.e. stopping the use of cigarettes or other tobacco products, May be defined in various ways; see also: point prevalence abstinence; prolonged abstinence; continuous/sustained abstinence

Also called 'biochemical validation' or 'biochemical confirmation':

A procedure for checking a tobacco user's report that he or she has not smoked or used tobacco. It can be measured by testing levels of nicotine or cotinine or other chemicals in blood, urine, or saliva, or by measuring levels of carbon monoxide in exhaled breath or in blood.

A pharmaceutical drug originally developed as an antidepressant, but now also licensed for smoking cessation; trade names Zyban, Wellbutrin (when prescribed as an antidepressant)

A colourless, odourless highly poisonous gas found in tobacco smoke and in the lungs of people who have recently smoked, or (in smaller amounts) in people who have been exposed to tobacco smoke. May be used for biochemical verification of abstinence.

Also called 'quitting'

The goal of treatment to help people achieve abstinence from smoking or other tobacco use, also used to describe the process of changing the behaviour

Also called 'sustained abstinence'

A measure of cessation often used in clinical trials involving avoidance of all tobacco use since the quit day until the time the assessment is made. The definition occasionally allows for lapses. This is the most rigorous measure of abstinence

Quitting abruptly, and/or quitting without behavioural or pharmaceutical support.

A very intense urge or desire [to smoke].

See: Shiffman et al 'Recommendations for the assessment of tobacco craving and withdrawal in smoking cessation trials'

Nicotine \& Tobacco Research 2004: 6(4): 599-614

A neurotransmitter in the brain which regulates mood, attention, pleasure, reward, motivation and movement

Also called 'treatment effect' or 'effect size':

The difference in outcome between the experimental and control groups

Strategies to reduce harm caused by continued tobacco/nicotine use, such as reducing the number of cigarettes smoked, or switching to different brands or products, e.g. potentially reduced exposure products (PREPs), smokeless tobacco.

Terms sometimes used for a return to tobacco use after a period of abstinence. A lapse or slip might be defined as a puff or two on a cigarette. This may proceed to relapse, or abstinence may be regained. Some definitions of continuous, sustained or prolonged abstinence require complete abstinence, but some allow for a limited number or duration of slips. People who lapse are very likely to relapse, but some treatments may have their effect by helping people recover from a lapse.

[neural nicotinic acetylcholine receptors]: Areas in the brain which are thought to respond to nicotine, forming the basis of nicotine addiction by stimulating the overflow of dopamine

An alkaloid derived from tobacco, responsible for the psychoactive and addictive effects of smoking. 
Nicotine Replacement Therapy (NRT)

Outcome

Pharmacotherapy

Point prevalence abstinence (PPA)

Prolonged abstinence

Relapse

Secondhand smoke

Self-efficacy

SPC [Summary of Product Characteristics]

Tapering

Titration

Withdrawal
A smoking cessation treatment in which nicotine from tobacco is replaced for a limited period by pharmaceutical nicotine. This reduces the craving and withdrawal experienced during the initial period of abstinence while users are learning to be tobacco-free The nicotine dose can be taken through the skin, using patches, by inhaling a spray, or by mouth using gum or lozenges.

Often used to describe the result being measured in trials that is of relevance to the review. For example smoking cessation is the outcome used in reviews of ways to help smokers quit. The exact outcome in terms of the definition of abstinence and the length of time that has elapsed since the quit attempt was made may vary from trial to trial.

A treatment using pharmaceutical drugs, e.g. NRT, bupropion

A measure of cessation based on behaviour at a particular point in time, or during a relatively brief specified period, e.g. 24 hours, 7 days. It may include a mixture of recent and long-term quitters. cf. prolonged abstinence, continuous abstinence

A measure of cessation which typically allows a 'grace period' following the quit date (usually of about two weeks), to allow for slips/lapses during the first few days when the effect of treatment may still be emerging.

See: Hughes et al 'Measures of abstinence in clinical trials: issues and recommendations'; Nicotine \& Tobacco Research, 2003: 5 (1); 13-25

A return to regular smoking after a period of abstinence

Also called passive smoking or environmental tobacco smoke [ETS]

A mixture of smoke exhaled by smokers and smoke released from smouldering cigarettes, cigars, pipes, bidis, etc. The smoke mixture contains gases and particulates, including nicotine, carcinogens and toxins.

The belief that one will be able to change one's behaviour, e.g. to quit smoking

Advice from the manufacturers of a drug, agreed with the relevant licensing authority, to enable health professionals to prescribe and use the treatment safely and effectively.

A gradual decrease in dose at the end of treatment, as an alternative to abruptly stopping treatment

A technique of dosing at low levels at the beginning of treatment, and gradually increasing to full dose over a few days, to allow the body to get used to the drug. It is designed to limit side effects.

A variety of behavioural, affective, cognitive and physiological symptoms, usually transient, which occur after use of an addictive drug is reduced or stopped.

See: Shiffman et al 'Recommendations for the assessment of tobacco craving and withdrawal in smoking cessation trials'

Nicotine \& Tobacco Research 2004: 6(4): 599-614

\section{A N A L Y S E S}

\section{Comparison 01. Rimonabant 20mg vs placebo}

\begin{tabular}{lcccc} 
Outcome title & $\begin{array}{c}\text { No. of } \\
\text { studies }\end{array}$ & $\begin{array}{c}\text { No. of } \\
\text { participants }\end{array}$ & Statistical method & Effect size \\
\hline 01 Prolonged abstinence at wk 50 & 2 & 1049 & Odds Ratio (Fixed) 95\% CI & $1.61[1.12,2.30]$ \\
02 Continuous 4-wk abstinence at & 2 & 1049 & Odds Ratio (Fixed) 95\% CI & $1.63[1.21,2.19]$ \\
EOT (wks 7-10) & & & & 14 \\
\hline \hline $\begin{array}{l}\text { Cannabinoid type I receptor antagonists (rimonabant) for smoking cessation (Review) } \\
\text { Copyright } \odot \text { 2007 The Cochrane Collaboration. Published by John Wiley \& Sons, Ltd }\end{array}$ &
\end{tabular}




\section{Comparison 02. Relapse prevention}

\begin{tabular}{lcccc} 
Outcome title & $\begin{array}{c}\text { No. of } \\
\text { studies }\end{array}$ & $\begin{array}{c}\text { No. of } \\
\text { participants }\end{array}$ & Statistical method & Effect size \\
\hline $\begin{array}{l}01 \text { rimonabant 20mg vs placebo at } \\
52 \text { weeks }\end{array}$ & 1 & 682 & Odds Ratio (Fixed) 95\% CI & $1.49[1.09,2.04]$ \\
02 rimonabant 5mg vs placebo at \\
52 weeks
\end{tabular}

Comparison 03. Rimonabant 5mg vs placebo

\begin{tabular}{lcccc} 
Outcome title & $\begin{array}{c}\text { No. of } \\
\text { studies }\end{array}$ & $\begin{array}{c}\text { No. of } \\
\text { participants }\end{array}$ & Statistical method & Effect size \\
\hline 01 Prolonged abstinence at wk 50 & 2 & 1039 & Odds Ratio (Fixed) 95\% CI & $1.13[0.77,1.66]$ \\
02 Continuous 4-wk abstinence at & 2 & 1039 & Odds Ratio (Fixed) 95\% CI & $1.15[0.84,1.56]$ \\
$\quad$ EOT (wks 7-10) & & & & \\
\hline
\end{tabular}

\section{Comparison 04. Rimonabant $20 \mathrm{mg}$ vs rimonabant $5 \mathrm{mg}$}

\begin{tabular}{lcccc} 
Outcome title & $\begin{array}{c}\text { No. of } \\
\text { studies }\end{array}$ & $\begin{array}{c}\text { No. of } \\
\text { participants }\end{array}$ & Statistical method & Effect size \\
\hline 01 Prolonged abstinence at wk 50 & 2 & 1046 & Odds Ratio (Fixed) 95\% CI & $1.42[1.00,2.02]$ \\
02 Continuous 4-wk abstinence at & 2 & 1046 & Odds Ratio (Fixed) 95\% CI & $1.42[1.06,1.90]$ \\
$\quad$ EOT (wks 7-10) & & & & \\
\hline
\end{tabular}

\section{COVER SHEET}

Title

Authors

Contribution of author(s)

Issue protocol first published

Review first published

Date of most recent amendment

Date of most recent

SUBSTANTIVE amendment

What's New

Date new studies sought but none found

Date new studies found but not yet included/excluded

Date new studies found and included/excluded

Date authors' conclusions section amended
Cannabinoid type 1 receptor antagonists (rimonabant) for smoking cessation

Cahill K, Ussher M

Both authors were involved in the conceptual and practical development of the review. $\mathrm{KC}$ primarily contributed to the smoking cessation sections, and MU to the weight gain sections, but both authors take responsibility for the content of the entire review.

$2005 / 3$

$2007 / 3$

11 May 2007

22 April 2007

Information not supplied by author Information not supplied by author

Information not supplied by author

Information not supplied by author

Information not supplied by author 


$\begin{array}{ll}\text { Contact address } & \text { Mrs Kate Cahill } \\ & \text { Co-ordinator, Cochrane Tobacco Addiction Group } \\ & \text { Department of Primary Health Care } \\ & \text { Old Road Campus } \\ \text { University of Oxford } & \text { Oxford } \\ & \text { OX3 7LF } \\ & \text { UK } \\ & \text { E-mail: kate.cahill@dphpc.ox.ac.uk } \\ & \text { Tel: }+441865289285 \\ & \text { Fax: }+441865289287 \\ & 10.1002 / 14651858 . C D 005353 . p u b 2 \\ & \text { CD005353 } \\ \text { DOI } & \text { Cochrane Tobacco Addiction Group } \\ \text { Cochrane Library number } & \text { HM-TOBACCO } \\ \text { Editorial group } & \end{array}$

GRAPHS ANDOTHER TABLES

\section{Analysis 01.0I. Comparison 0I Rimonabant 20mg vs placebo, Outcome 0 I Prolonged abstinence at wk 50}

Review: Cannabinoid type I receptor antagonists (rimonabant) for smoking cessation

Comparison: 0 I Rimonabant 20mg vs placebo

Outcome: 01 Prolonged abstinence at wk 50

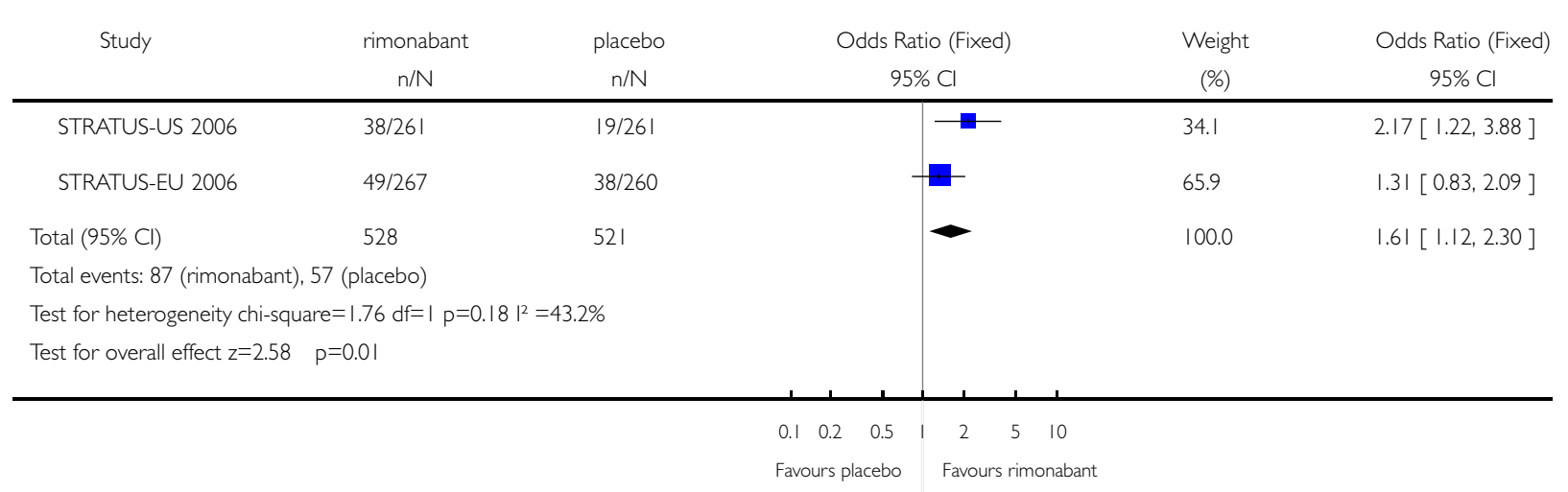


Analysis 01.02. Comparison 01 Rimonabant 20mg vs placebo, Outcome 02 Continuous 4-wk abstinence at EOT (wks 7-10)

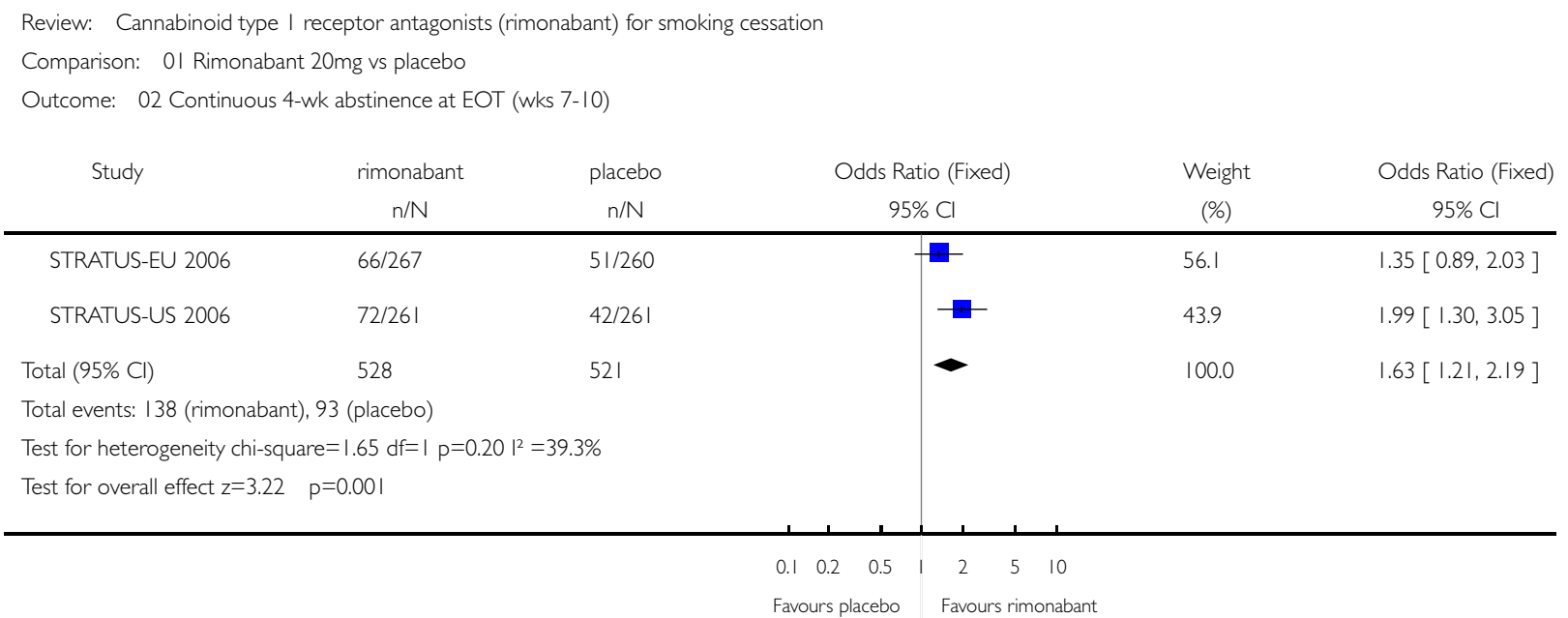

\section{Analysis 02.01 . Comparison 02 Relapse prevention, Outcome 01 rimonabant $20 \mathrm{mg}$ vs placebo at 52 weeks}

Review: Cannabinoid type I receptor antagonists (rimonabant) for smoking cessation

Comparison: 02 Relapse prevention

Outcome: 01 rimonabant $20 \mathrm{mg}$ vs placebo at 52 weeks

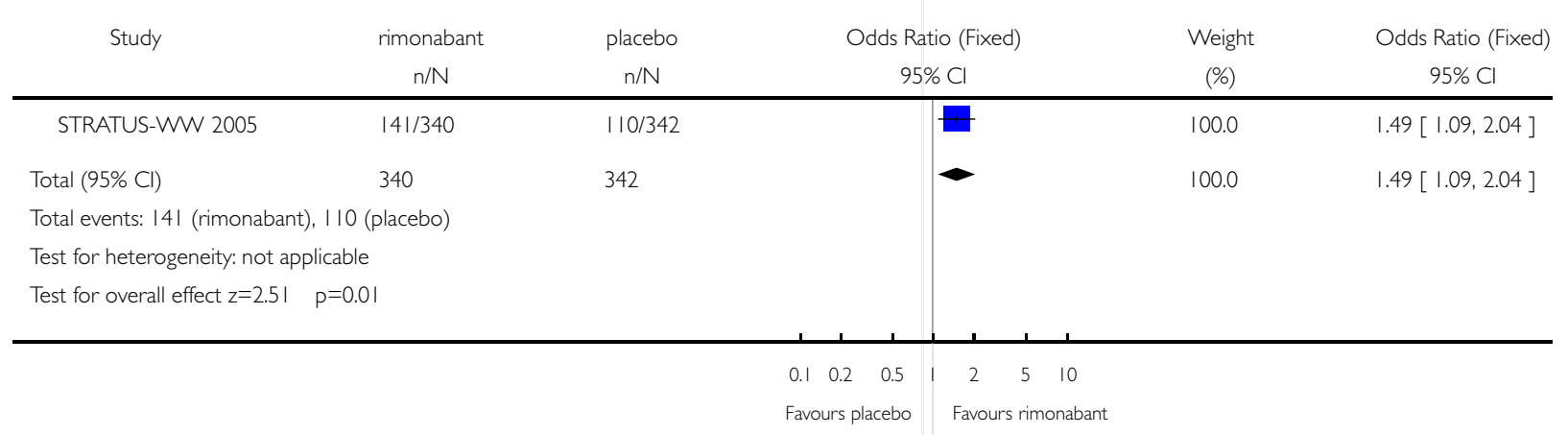




\section{Analysis 02.02. Comparison 02 Relapse prevention, Outcome 02 rimonabant $5 \mathrm{mg}$ vs placebo at 52 weeks}

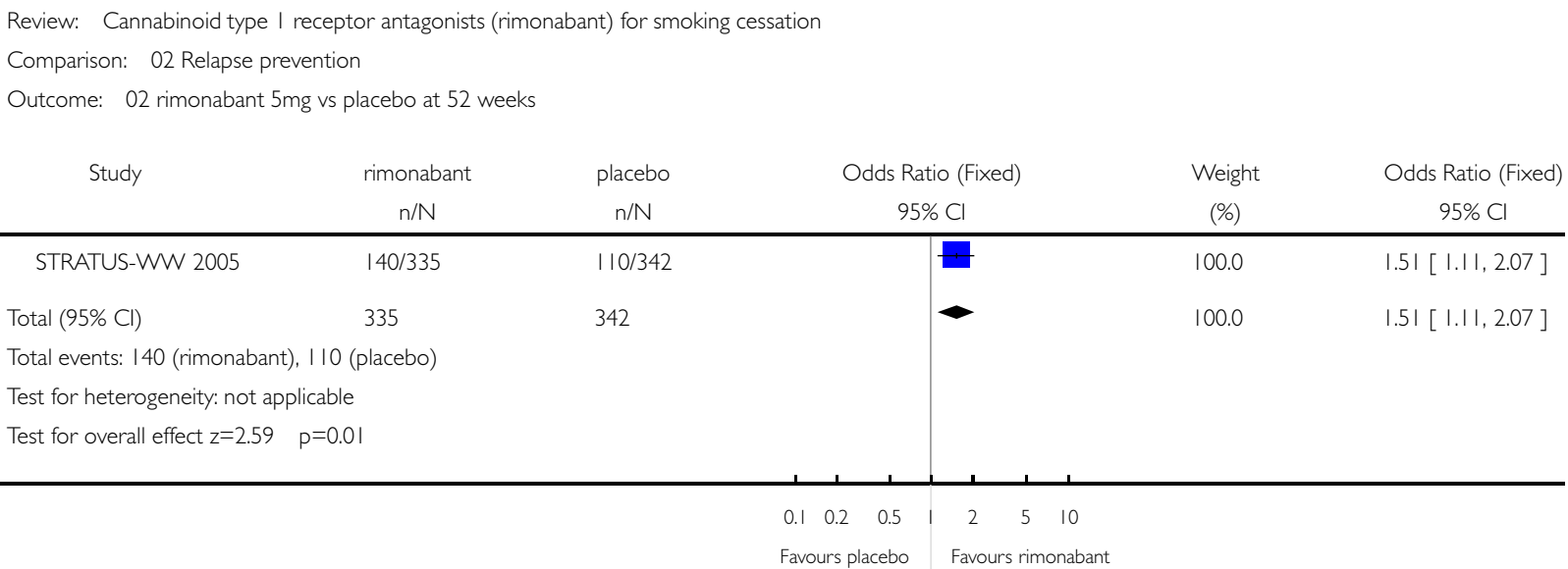

\section{Analysis 03.0I. Comparison 03 Rimonabant $5 \mathrm{mg}$ vs placebo, Outcome 01 Prolonged abstinence at wk $\mathbf{5 0}$}

Review: Cannabinoid type I receptor antagonists (rimonabant) for smoking cessation

Comparison: 03 Rimonabant $5 \mathrm{mg}$ vs placebo

Outcome: 01 Prolonged abstinence at wk 50

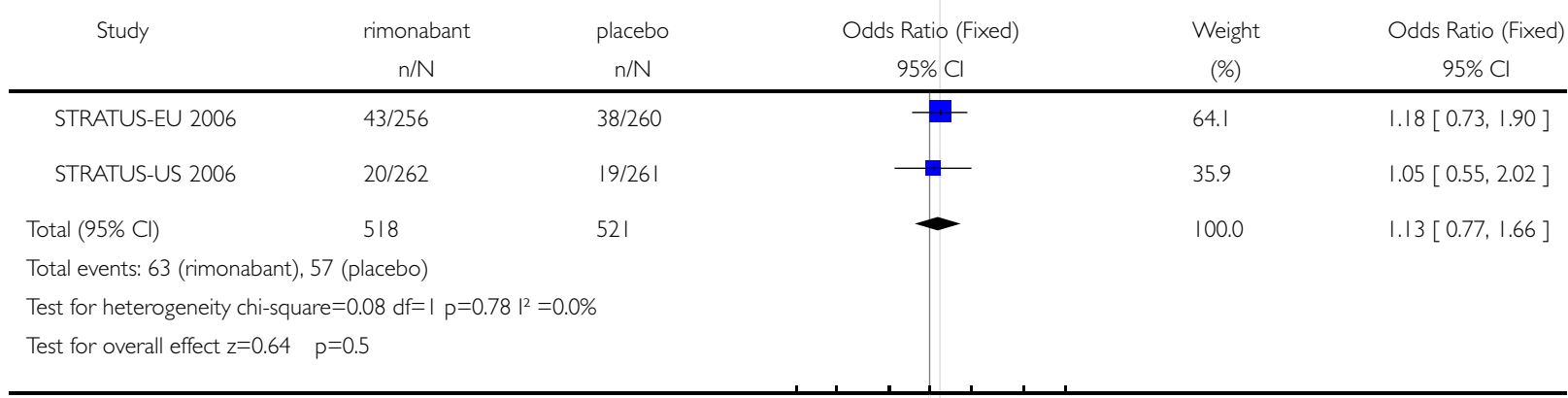

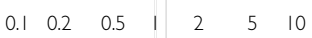

Favours placebo Favours rimonabant 


\section{Analysis 03.02. Comparison 03 Rimonabant $5 \mathrm{mg}$ vs placebo, Outcome 02 Continuous 4-wk abstinence at}

EOT (wks 7-10)

Review: Cannabinoid type I receptor antagonists (rimonabant) for smoking cessation

Comparison: 03 Rimonabant $5 \mathrm{mg}$ vs placebo

Outcome: 02 Continuous 4-wk abstinence at EOT (wks 7-10)

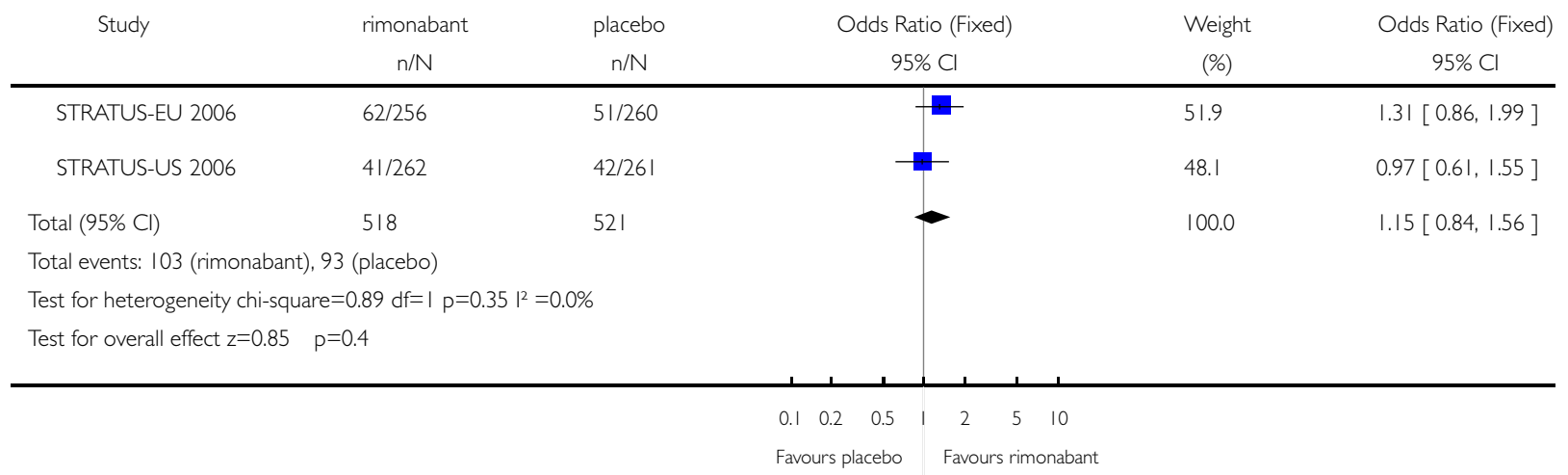

\section{Analysis 04.0I. Comparison 04 Rimonabant $20 \mathrm{mg}$ vs rimonabant $5 \mathrm{mg}$, Outcome 0 I Prolonged abstinence at} wk 50

Review: Cannabinoid type I receptor antagonists (rimonabant) for smoking cessation

Comparison: 04 Rimonabant $20 \mathrm{mg}$ vs rimonabant $5 \mathrm{mg}$

Outcome: 0 I Prolonged abstinence at wk 50

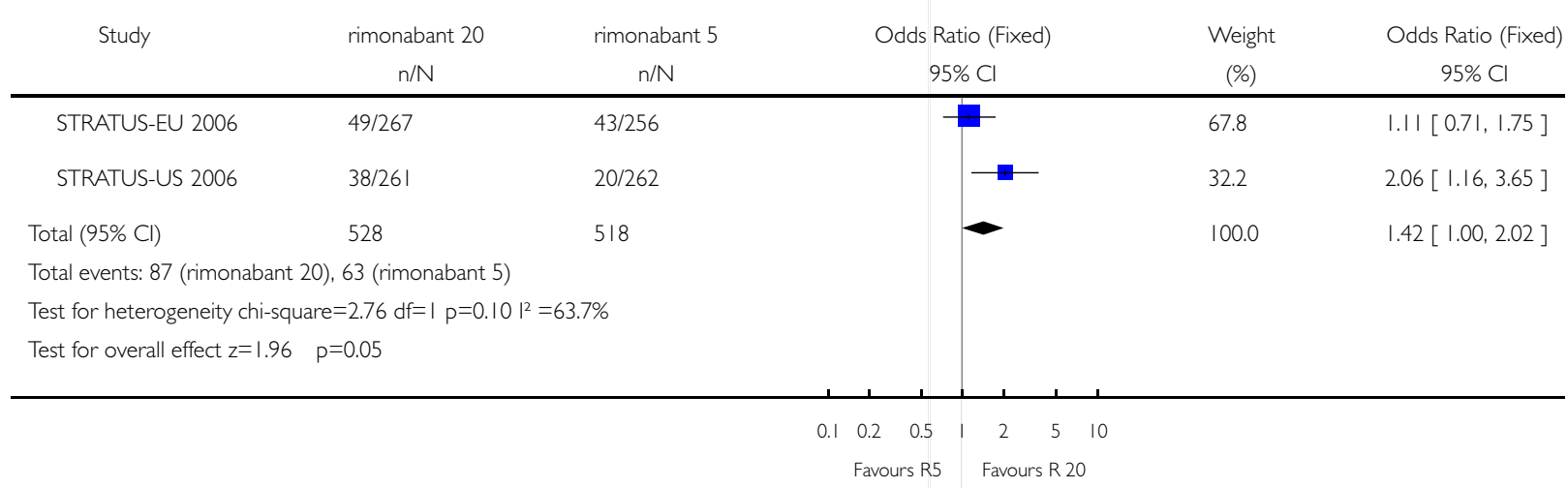




\section{Analysis 04.02. Comparison 04 Rimonabant $20 \mathrm{mg}$ vs rimonabant $5 \mathrm{mg}$, Outcome 02 Continuous 4-wk}

abstinence at EOT (wks 7-10)

Review: Cannabinoid type I receptor antagonists (rimonabant) for smoking cessation

Comparison: 04 Rimonabant 20mg vs rimonabant $5 \mathrm{mg}$

Outcome: 02 Continuous 4-wk abstinence at EOT (wks 7-10)

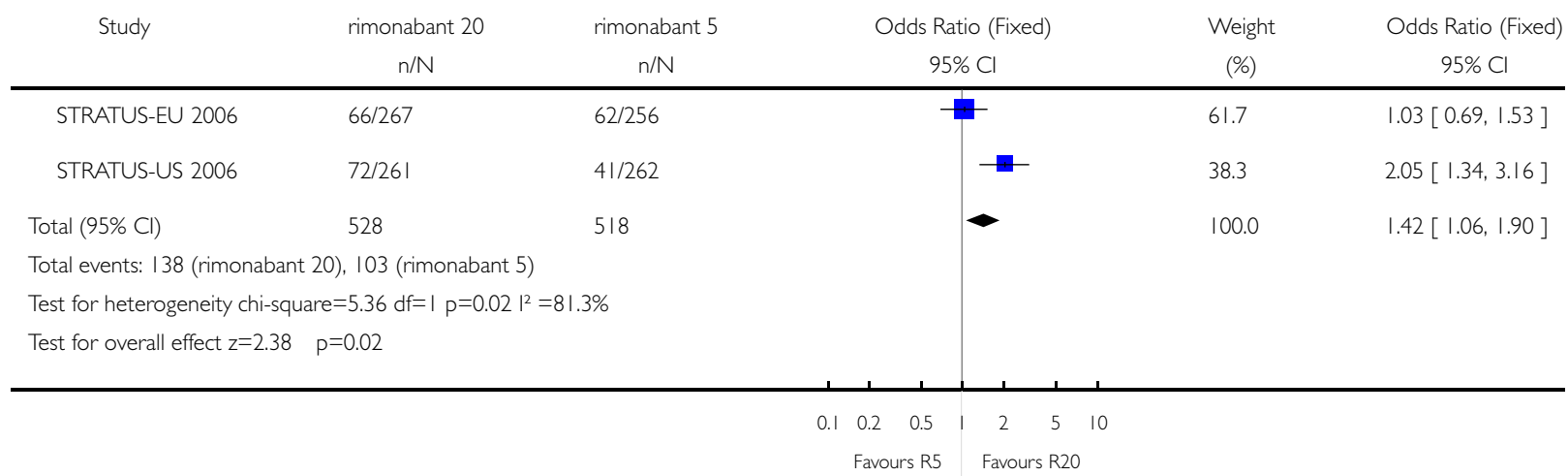

